\title{
Topical Diltiazem Versus Topical Glyceryl Trinitrate in the Management of Chronic Anal Fissure
}

\author{
Shams ul Bari, M.S. ', Ajaz Ahmad Malik, M.S. ${ }^{2}$, K Alam Wani, M.S. ${ }^{2}$, Ajaz A Rather, M.S. ${ }^{1}$
}

2Departments of General \& Minimal Access Surgery, SKIMS, Soura and

'SKIMS Medical College Bemina Srinagar Kashmir, India.

\section{A B S T RA C T}

Background: Chemical sphincterotomy is a novel way for treating patients of chronic anal fissure which avoids the risk of fecal incontinence associated with traditional surgical methods.

Aims and objectives: The aim of this study was to compare the results of topical Diltiazem with topical Glyceril trinitrate in the management of chronic anal fissure.

Methods: 71 patients in the age group of 15-61 years with chronic anal fissure were included in this prospective, randomized, double-blind trial over a period of two years with further follow up for one year. The patients were randomly allocated to either Diltiazem gel $2 \%$ ( 37 patients) or Glyceril trinitrate ointment $0.2 \%$ (34 patients) and were asked to use the treatment twice daily for 8 weeks. Each patient was reviewed every two weeks. Symptoms, healing, side effects and recurrence were compared using SPSS version 10 employing X2 test. A p-value below 0.05 was considered statistically significant.

Results: Patients who received topical diltiazem (DTZ) showed statistically significant difference than those who were prescribed topical glyceril trinitrate in terms of symptoms, wound healing, side effects ( headaches) and recurrence ( $p=0.03$ and 0.003 respectively). Healing occurred in 34 of $37(92 \%)$ patients treated with Diltiazem after 6 weeks and 27 of $34(80 \%)$ patients treated with Glyceril trinitrate after 8 weeks, which shows a significant difference in favour of Diltiazem $(P<0.001)$. The rest of the patients did not heal and underwent sphincterotomy (SILS). Headache occurred in all of the patients treated with Glyceril trinitrate but none of the patients treated with Diltiazem.

Conclusion: Diltiazem gel was found to be better than Glyceril trinitrate ointment due to significantly higher healing rate and fewer side-effects. JMS 2014; 17(2):55-58

Keywords: Fissure, DTZ,AIDS

\section{INTRODUCTION}

Anal fissures or fissure-in-ano is a common condition that can cause severe anal pain after defecation, bleeding and pruritis ani. It is a linear longitudinal tear in the lining of the anal canal that extends from the dentate line to the anal verge. In $90 \%$ cases the tear is located in the posterior midline ${ }^{1}$. The majority of anal fissures are acute and selflimiting with simple conservative dietary measures. Fissures that fail to resolve after 6 weeks are defined as chronic and these usually require pharmacological or surgical intervention to promote healing ${ }^{1}$.

Untill approximately 5 years ago, lateral internal sphincterotomy was the gold standard in treatment, producing rapid symptom relief and healing rates of over

\section{Correspondence}

Dr. Shams ul Bari, M.S.

Assistant Professor, Department of Surgery,

SKIMS Medical College Srinagar, Kashmir India

e-mail : shamsulbari@rediffmail.com /

ajazamalik@yahoo.com
$90 \%$, but it is now less popular as disturbances in continence can occur in up to $30 \%$ of patients ${ }^{2}$. Pharmacological agents such as nitrates, calcium channel blockers like diltiazem, nifedipine and botulinum toxin have largely replaced surgery as first line therapy for anal fissures. They reduce anal hypertonia by causing reversible sphincterotomy and thereby avoiding incontinence ${ }^{2,3}$.

\section{METHODS}

This study was conducted jointly in the departments of surgery at Sher-i-Kashmir Institute of Medical Science (SKIMS) Soura and SKIMS Medical college Bemina Srinagar, Kashmir India over a period of 2 years from January 2010 to December 2011 with further follow up for a period of one year. It was a prospective, randomized, double-blind study. Total number of patients studied was 71.It included 28 males and 43 females in the age group of 15 to 61 years. All the patients were subjected to detailed history and physical examination, along with all base line investigations including haemogram, kidney function tests, 
blood sugar, ECG and x-ray chest. Perianal examination revealed a tightly closed and puckered anus. On gentle parting of the buttocks, the lower end of the fissures is seen. Digital examination of the anal canal was not attempted.

All the patients were put on high fibre diet, increased water intake, stool softeners and warm sitz baths. The patients were randomly put on either Diltiazem gel 2\% (37patients) or Glyceril trinitrate ointment $0.2 \%$ (34 patients) and were asked to use the treatment twice daily for 8 weeks. Patients were reviewed every two weeks to see the response to the treatment. Symptoms, healing of the fissure, side effects and recurrences were compared. Data was analyzed using SPSS version 10 using $\mathrm{X} 2$ test. A p-value below 0.05 was considered statistically significant.

\section{RESULTS AND OBSERVATIONS}

Our patients were in the age group of 15 to 61 years with a median age of 33 years. Our study included 28 males and 43 females with 38 patients belonging to rural and 33 to urban areas. Pain was seen in all the 71 patients, while as bleeding with stool was seen in $60(84.5 \%)$ patients. Constipation was seen in all the $71(90 \%)$ patients. A single posterior linear tear in anal mucosa was seen in $61(86 \%)$ patients, with anterior midline fissure in $8(11.5 \%)$ and multiple lateral tears in $2(2.8 \%)$ patients. 7 patients with anterior fissure were females with history of child birth during last 6 months in 5 females.

Patients who received topical diltiazem (DTZ) showed statistically significant difference than those who were prescribed topical glyceril trinitrate in terms of symptoms, wound healing and side effects (headaches). Fissure healed in 34 of $37(92 \%)$ patients treated with Diltiazem after 6 weeks and 27 of $34(80 \%)$ patients treated with Glyceril trinitrate after 8 weeks which shows a significant difference in favour of Diltiazem $(P<0.001)$. Fissure failed to heal in 10 patients and these patients underwent sphinterotomy. Headache as side effect was seen in all patients treated with Glyceril trinitrate. On the other hand none of the patients treated with glyceryl trinitrate had headache. There was no relapse in any of these patients during a follow up period of one year.

\section{DISCUSSION}

An anal fissure is a break or tear in the skin of the anal canal ${ }^{1-}$

${ }^{5}$ Patients give history of bright red anal bleeding and the bleeding is separate from the stool and is usually modest. If acute they may cause pain after defecation but with chronic fissures pain intensity is often less. Anal fissures usually extend from the anal opening to dentate line and most of them are located posteriorly in the midline, probably because of the relatively unsupported nature and poor perfusion of the anal wall in that area. Fissure depth may be superficial or sometimes down to the underlying sphincter muscle.

The incidence of anal fissures is around 1 in 350 adults and occur equally in men and women and most of the patients are in the age group of 15 to 40 years ${ }^{5,7}$. In adults, fissures are most commonly caused by constipation due to the passing of large, hard stools, or by prolonged diarrhea. In older adults, anal fissures may be caused by decreased blood flow to the area. When fissures are found laterally, tuberculosis, occult abscesses, leukemic infiltrates, carcinoma, acquired immunodeficiency syndrome (AIDS) or inflammatory bowel disease should be considered as causes. Certain sexually transmitted infections can also lead to breakdown of tissue resulting in a fissure such as syphilis, herpes, chlamydia and human papilloma virus. Child birth as a cause of fissures has been seen in 3-11 \% females with fissures ${ }^{3,7-9}$.

Fissures can be prevented by avoiding straining while defecating. This includes treating and preventing constipation by eating food rich in dietary fiber, drinking enough water and use of a stool softener. Similarly, prompt treatment of diarrhea may reduce anal strain. Careful anal hygiene after defecation, including using soft toilet paper and/or cleaning with water also gives prevention from fissures. In infants, frequent diaper change can prevent anal fissure.

Initially non-surgical methods are recommended for treatment of acute and chronic anal fissures ${ }^{7.8}$ These include topical nitroglycerin or calcium channel blockers or injection of botulinum toxin into the anal sphincter ${ }^{16}$. A common side effect of nitroglycerine ointment is headache, caused by systemic absorption of the drug, which limits patient acceptability ${ }^{9}$. In addition to it warm sitz baths, topical anesthetics, high-fiber diet and stool softeners are advised $^{10,11}$.

Local application of medications to relax the sphincter muscle, thus allowing the healing to proceed, was first proposed in 1994 with nitroglycerine ointment ${ }^{12-19}$ and then calcium channel blockers ${ }^{12,13,14}$ in 1999 ,followed by use of nifedipine ointment $t^{13,14,15,16,20}$ in the following year with topical diltiazem ${ }^{14,21,2,2,23}$. 
Puche JJ, et $\mathrm{al}^{24}$, conducted a study comprising of 145 patients. The patients were divided into two groups. One group was treated with nitroglycerine (NTG) $0.2 \%$ and the other group was put on diltiazem $2 \%$. They reported symptomatic relief in $62.5 \%$ treated with NTG and $80 \%$ patients treated with diltiazem. They concluded that although both provided good symptomatic relief thereby avoiding surgery but there were more side effects and more drop outs in NTG group.

Ala $\mathrm{S}$ et $\mathrm{al}^{25}$, conducted a double blind randomized study on 61 patients. The patients were randomly allocated either Diltiazem gel $(2 \%)$ or Glyceril trinitrate ointment $(0.2 \%)$ and were asked to use the treatment twice daily for 8 weeks. Diltiazem gel was found to be superior to Glyceril trinitrate ointment due to significantly higher healing rate $(91 \%$ vs $60 \%$ ) and fewer side-effects.

Another study was conducted by Hashmi F and Siddiqui FG(26), to assess and compare the effectiveness of topical $0.2 \%$ glycerl trinitrate (50 patients) and topical 2\% diltiazem (47 patients), in the management of chronic anal fissure. Symptoms, recurrence, wound healing and side effects were compared. They concluded that chemical sphincterotomy is an effective first line management for chronic anal fissure. Although both GTN and DTZ are equally effective in managing the chronic anal fissure but DTZ has fewer side effects, a better healing response and low recurrence rates.

The results of our study are in agreement with the results of these studies. In our study, fissures healed in $92 \%$ patients treated with Diltiazem after 6 weeks and $80 \%$ patients treated with Glyceril trinitrate after 8 weeks. Headache was seen in all patients treated with Glyceril trinitrate. On the other hand none of the patients treated with glyceryl trinitrate had headache. There was no relapse in any of these patients during a follow up period of one year.

\section{CONCLUSION}

Chemical sphincterotomy is an effective first line management for chronic anal fissure and offers more symptomatic relief, providing an opportunity to avoid surgery. Although both diltiazem and nitroglycerine are very effective in managing chronic anal fissures, Diltiazem gel was found to be better than Glyceril trinitrate ointment due to significantly higher healing rate. Topical diltiazem does not have the side effects of the nitroglycerin and is better accepted by patients.

\section{REFERENCES}

1. Malik AA, Bari S. Conservative management of anal fissures. J.Med .Sci.2009;12(1), 14-16.

2. Collins, E.E.; Lund, J.N. "A Review of Chronic Anal Fissure Management". Techniques in Coloproctology, September 2007,11 (3): 209-223.

3. Acheson, A.G., Griffin, N. and Sholefield, J.H.The role of botulinum toxin in gastro intestinal surgery. Recent advances in surgery 2002, vol.25, P.No.59-70.

4. "Anal Fissure - Basics - Epidemiology" Best Practice. British Medical Journal. Apr 23, 2012.

5. Nelson RL, Thomas K, Morgan J, Jones A. "Nonsurgical therapy for anal fissure". Cochrane Database Syst Rev 2: 2012.

6. Jonas M, Scholefield, JH. Anal fissure and chemical sphincterotomy. Recent advances in surgery 2001, Vol 24, P.no. 115-123.

7. Sailer M, Bussen D, Debus ES, Fuchs KH, Thiede A. Quality of life in patients with benign anorectal disorders. Br. J surg. 1998:85: 1716-1719

8. Lund JN. Scholefield JH. A Randomised, Prospective, doubleblind, Placebocontrolled trial of glyceryl trinitrate ointment in the treatment of anal fissure. Lancet 1997:349:11-14.

9. Schouten WR, Briel JW, Boerma Mo, Aumerda JJA. Pathophysiological aspects and clinical outcome of intra anal application of isosorbide dinitrate in patients with chronic anal fissure. Gut 1995:36:A16.

10. Lysy J, Israelit-Yatzkan Y, Sestiere-ittah M, Keret D, Goldin E. Treatment of chronic anal fissure with isosorbide-dinitrate. Long term results and dose determination. Dis colon Rectum 1998:41: 14061410.

11. Dorfman G, Levitt M, Platell C. Treatment of chronic anal fissure with topical glyceryl trinitate. Dis colon rectum 1999:42: 1007-1010.

12. Hasegawa H, Radley S, Morton DG, dorricott NG, Audit of topical glyceryl trinitrate for treatment of fissure in ano. Ann R Coll surg engl.2000:82:27-30.

13. Cook T1, Smilgin Humphreys MM Mcmortensen NJ, Oral nifedipine is an effective treatment for chronic anal fissures. Colorectal Dis 1999: I:55.

14. Jones M, Scholefield JH. Oral and topical dilitazem are 
effective treatment for chronic anal fissures. Gut 2000: 46: A83

15. Haq, Z.; Rahman, M.; Chowdhury, R.; Baten, M.; Khatun, M. "Chemical SphincterotomyFirst Line of Treatment for Chronic Anal Fissure". Mymensingh Medical Journal, 2005, 14 (1): 88-90.

16. Shao, WJ; Li, G C, Zhang, ZK (2009 Sep). "Systematic review and meta-analysis of randomized controlled trials comparing botulinum toxin injection with lateral internal sphincterotomy for chronic anal fissure". International journal of colorectal disease, 2009, 24 (9): 995-1000.

17. Loder, P.; Kamm, M.; Nicholls, R.; Phillips, R. "'Reversible Chemical Sphincterotomy' by Local Application of Glyceryl Trinitrate". British Journal of Surgery 1994,81 (9): 1386-1389.

18. Watson, S.; Kamm, M.; Nicholls, R.; Phillips, R. "Topical Glyceryl Trinitrate in the Treatment of Chronic Anal Fissure". British Journal of Surgery 1996, 83 (6): 771-775.

19. Simpson, J.; Lund, J.; Thompson, R.; Kapila, L.; Scholefield, J. "The Use of Glyceryl Trinitrate (GTN) in the Treatment of Chronic Anal Fissure in Children". Medical Science Monitor, 2003,

20. Katsinelos, P.; Kountouras, J.;Paroutoglou, G.; Beltsis, A.; Chatzimavroudis, G.; Zavos, C.; Katsinelos, T.; Papaziogas, B. (2006). "Aggressive Treatment of Acute Anal Fissure with $0.5 \%$ Nifedipine Ointment Prevents Its Evolution to Chronicity". World Journal of Gastroenteroloogy 2006,12 (38): 6203-6206.
21. Carapeti, E.; Kamm, M.; Phillips, R. (2000). "Topical Diltiazem and Bethanechol Decrease Anal Sphincter Pressure and Heal Anal Fissures without Side Effects". Diseases of the Colon and Rectum 2000, 43 (10): 1359-1362.

22. Sadovsky, R. "Diagnosis and management of patients with anal fissures - Tips from Other Journals"(Reprint). American Family Physician 2003, 67 (7): 160

23. Lund, J. N.; Nyström, P. O.; Coremans, G.; Herold, A.; Karaitianos, I.; Spyrou, M.; Schouten, W. R.; Sebastian, A. A.; Pescatori, M. (October 2006). "An evidence-based treatment algorithm for anal fissure". Techniques in Coloproctology 2006, 10 (3): 177-180.

24. Puche JJ ,Garcia-Coret MJ ,Vallalba FL, AliMohamoud I,Roig J; Local treatment of a chronic anal fissure with diltiazem vs. nitroglycerin. A comparative study]. Cir Esp. 2010 Apr; 87(4):224-30.

25. Ala S, Saeedi M, Hadianamrei R, Ghorbanian A; Topical diltiazem vs. topical glyceril trinitrate in the treatment of chronic anal fissure: a prospective, randomized, double-blind trial. Acta Gastroenterol Belg. 2012 Dec;75(4):438-42.

26. Hashmi F, Siddiqui FG; Diltiazem (2\%) versus glyceryl trinitrate cream $(0.2 \%)$ in the management of chronic anal fissure; J Coll Physcians Surg Pak, 2009 Dec;19(12):750-3 